\title{
Modification of Butterfat by Selective Hydrolysis and Interesterification by Lipase: Process and Product Characterization
}

\author{
Victor M. Balcão ${ }^{a}$, Asmo Kemppinen ${ }^{b}$, F. Xavier Malcata ${ }^{a, *}$, and Paavo J. Kalo ${ }^{c}$ \\ ${ }^{a}$ Escola Superior de Biotecnologia, Universidade Católica Portuguesa, 4200 Porto, Portugal, and Departments of ${ }^{b}$ Food \\ Technology and ${ }^{C}$ Applied Chemistry and Microbiology, University of Helsinki, Viikki 00014, Finland
}

\begin{abstract}
Butterfat was chemically modified via combined hydrolysis and interesterification, catalyzed by a commercial lipase immobilized onto a bundle of hydrophobic hollow fibers. The main goal of this research effort was to engineer butterfat with improved nutritional properties by taking advantage of the sn-1,3 specificity and fatty acid specificity of a lipase in hydrolysis and ester interchange reactions, and concomitantly decrease its level of long-chain saturated fatty acid residues (viz., lauric, myristic, and palmitic acids) and change its melting properties. All reactions were carried out at $40^{\circ} \mathrm{C}$ in a solventfree system under controlled water activity, and their extent was monitored via chromatographic assays for free fatty acids, esterified fatty acid moieties, and triacylglycerols; the thermal behavior of the modified butterfat was also assessed via calorimetry. Lipase-modified butterfat possesses a wider melting temperature range than regular butterfat. The total saturated triacylglycerols decreased by $2.2 \%$, whereas triacylglycerols with 28-46 acyl carbons (which contained two or three lauric, myristic, or palmitic acid moieties) decreased by $13 \%$. The total monoene triacylglycerols increased by $5.4 \%$, whereas polyene triacylglycerols decreased by $2.9 \%$. The triacylglycerols of interesterified butterfat had ca. $10.9 \%$ less lauric, $10.7 \%$ less myristic, and $13.6 \%$ less palmitic acid residues than those of the original butterfat.
\end{abstract}

KEY WORDS: Fats, hollow-fiber bioreactor, immobilized lipase, interesterification, melting point, Mucor javanicus.

Oils and fats from natural sources are mixtures of various types of triacylglycerols (TAG) that contain different combinations of fatty acid moieties. The chainlength of the fatty acid residues, their degree of unsaturation, and their binding position on the glycerol backbone do all influence the bulk physical and chemical properties of those oils and fats. Butterfat, for example, is a mixture of more than 10,000 different TAG with a melting range from $c a .-40$ to $40^{\circ} \mathrm{C}$ (1); as many as $c a .400$ different fatty acid moieties have been reported to exist in butterfat (2), $25 \%$ of which are accounted for by short-chain saturated residues and $45 \%$ by long-chain saturated residues (3). Nutritionally, butterfat contains a high per- centage of hypercholesterolemic (long-chain) saturated fatty acids, located predominantly at the $s n-2$ position of the TAG (4). This myriad of TAG and fatty acid moieties contributes to the unique flavor and physical properties of butterfat (5), and the medium- and long-chain saturated fatty acids and their stereochemical distribution among the glycerol backbones give rise to relatively high melting points (6). Engineering of oils and fats may thus take the form of deliberate changes in the combination of fatty acid residues in the glycerol backbone of triglycerides to aim at, e.g., widening the melting range or increasing stability against oxidation (7).

Technologies for modification of oils and fats that have met with commercial success make use of mixing, hydrogenation, fractionation, chemical interesterification, and bulk chemical synthesis. However, these processes are aggressive to edible oils and fats because of their use of chemical reactants and solvents under high temperatures, and thus they often require post-processing refining. Such drawbacks have launched increased interest toward lipase-catalyzed reactions, because these enzymes, in addition to exhibiting high activity under mild environmental conditions, possess unusual selectivity and specificity toward their natural substrates (i.e., fatty acid moieties), and in their action they mimic environmentfriendly (bio)chemical routes. Interesterifications are preferably carried out in hydrocarbon solvents, which facilitate the reaction by lowering the viscosity of the reaction medium; however, then the reaction product has to be bleached and deodorized for nutritional safety (8). Therefore, interesterification in the absence of solvents has been preferred by an increasing number of researchers (8-10), although solvent-free systems require higher processing temperatures. Moreover, by using an $s n$-1,3-specific lipase, the exchange of acyl moieties is confined to the $s n-1$ and $s n-3$ positions, thus giving rise to a product with characteristics that cannot be obtained by conventional chemical (random) interesterification $(11,12)$.

In this work, the lipase-catalyzed selective hydrolysis and interesterification of anhydrous butterfat were studied in a solvent-free system by means of a lipase produced by the mold Mucor javanicus and immobilized by adsorption onto a bundle of hydrophobic hollow fibers. This lipase hydrolyzes

*To whom correspondence should be addressed. 
specifically the acyl moieties esterified to the outer positions of the glycerol backbone and has been reported to display specificity for medium- to long-chain fatty acid moieties (13-15). Such a combined process aims at producing butterfat with tentatively improved nutritional properties, by partial depletion of lauric, myristic, and palmitic acid moieties and a widened melting spectrum, via a processing system that is rather inexpensive in terms of enzyme utilization and support regeneration.

\section{EXPERIMENTAL PROCEDURES}

Enzyme. The lipase used (obtained from M. javanicus) was a commercial crude powder (M10 ${ }^{\mathrm{TM}}$ ) from Amano Pharmaceutical (Nagoya, Japan). The enzyme was immobilized by plain physical adsorption onto polypropylene fibers. A (bovine) pancreatic lipase (Sigma, St. Louis, MO) was also used for analytical purposes.

Processing apparatus. A laboratory module of microporous polypropylene hollow fibers (Liqui-Cell ${ }^{\mathrm{TM}} \mathrm{X} 10 / 240$ ) was purchased from Hoechst Celanese (Charlotte, NC). This laboratory unit, $30 \mathrm{~cm}$ long and $2.5 \mathrm{~cm}$ in diameter, contains $c a .2100$ (hydrophobic) fibers ( $c a .16 \mathrm{~cm}$ long) with a nominal internal diameter of $240 \mu \mathrm{m}$, a nominal porosity of $c a$. 0.30 , and nominal pore dimensions of $0.050 \times 0.150 \mu \mathrm{m}$ (width $\times$ length); the resulting effective membrane area is thus ca. $0.23 \mathrm{~m}^{2}$. The fibers are manufactured by a process that involves stretching of extruded polypropylene in a heat tunnel. The water bath was equipped with a mechanical agitator and a digital temperature controller (Julabo Labortechnik, Seelbach, Germany). Recirculation of fluids was achieved with high-precision metering pumps (ISMATEC MC-Z, Zürich, Switzerland).

Chemicals. Diethyl ether, isooctane, albumin fraction V (from bovine blood serum), sodium hydroxide, and hexane were obtained from Merck (Darmstadt, Germany); chloroform, acetonitrile $\left(190^{\mathrm{TM}}\right)$, and methanol $\left(205^{\mathrm{TM}}\right)$ were from ROMIL Chemicals (Leicester, United Kingdom); 2,7-dichlorofluorescein was purchased from BDH Chemicals (Poole, United Kingdom); acetone and acetic acid were purchased from Riedel-de-Haën (Seelze, Germany); isooctane, pentane, and dichloromethane were purchased from Rathburn Chemicals (Walkerburn, Scotland, United Kingdom). Monoacid TAG standards (99\% purity) were purchased from Sigma and Fluka (Buchs, Switzerland). Free fatty acid standards ( $>99.9$ $\%$ pure) and tripelargonin were obtained from Sigma. $p$ Propylbenzene sulfonic acid sorbent was purchased from International Sorbent Technologies (Tir-y-berth Hengoed, Mid Glamorgan, United Kingdom). Fermentation ethanol (96\% $\mathrm{vol} / \mathrm{vol}$ ) was obtained from AGA (Sacavém, Portugal). Dry nitrogen $\left(\mathrm{C}-55^{\mathrm{TM}}\right)\left(<1 \mathrm{ppm}_{2} \mathrm{O}\right.$ and $\left.<1 \mathrm{vpm} \mathrm{O}_{2}\right)$ and liquid nitrogen were purchased from Carburos Metalicos (Barcelona, Spain). All chemicals employed were reagent grade (or better, where indicated) and were used without further purification. Tap water was subject to successive steps of reverse osmosis, adsorption, deionization, microfiltration, and photo-oxidation in a Milli-Q Plus 185 water purification system (Molsheim, France) to a final conductivity of 18.2 $\mathrm{M} \Omega \cdot \mathrm{cm}^{-1}$. The standard mixture GLC74 of fatty acid methyl esters was purchased from Nu-Chek-Prep (Elysian, MN), whereas the standard mixtures of branched-chain fatty acid methyl esters (FAME) (89-1052 Qual Mix BR2 and 89-1054 Qual Mix BR4) were purchased from Larodan Fine Chemicals (Malmö, Sweden).

Substrate. Salt-free, pasteurized cow's butter was purchased from Proleite (Oliveira de Azeméis, Portugal) and kept in sealed plastic bags of $c a .1 .5 \mathrm{~kg}$ at $-30^{\circ} \mathrm{C}$ until experimental use.

Analytical equipment. Nylon membrane filters (Nalgene $^{\mathrm{TM}}, 0.45 \mu \mathrm{m}$ ) were purchased from Nalge (New York, NY). Disposable cuvettes for the spectrophotometric readings were purchased from Kartell (Binasco, Italy). Karl-Fischer titration was carried out with a $684 \mathrm{KF}$ Coulometer (Metrohm, Herisau, Switzerland). The differential scanning calorimeter (Shimadzu, Kyoto, Japan) consisted of a detector (DSC-50), coupled with a thermal analyzer (TA-501). Two gas chromatography (GC) systems were utilized: one GC was from Carlo Erba (Milan, Italy) and consisted of a Model HRGC 5300, equipped with an on-column injector, a flameionization detector (FID), a constant pressure/constant flow module, and a 25-m, $0.25 \mathrm{~mm}$ i.d., polarizable phenyl(65\%)methylsilicone column (Quadrex, New Haven, CT) with $0.1 \mu \mathrm{m}$ film thickness; data acquisition and integration were carried out with an SC chromatographic workstation (Version 1.2B; Sunicom Oy, Helsinki, Finland); the other GC was a MicroMat model HRGC 412 (HNU-Nordion, Helsinki, Finland), equipped with a split-splitless injector, an FID, and an HP-INNOWAX (crosslinked polyethylene glycol) silica capillary column $(30 \mathrm{~m} \times 0.25 \mathrm{~mm}$ i.d.) (Hewlett-Packard, Avondale, PA) with $0.25 \mu \mathrm{m}$ film thickness. The solvent evaporation unit consisted of a Pierce Reacti-Therm ${ }^{\mathrm{TM}}$ heating module (Model 187980; Pierce Chemical, Rockford, IL) coupled with a Pierce Reacti-Vap ${ }^{\mathrm{TM}}$ evaporating unit (model 18780). Thin-layer silica gel G plates, $20 \mathrm{~cm} \times 20 \mathrm{~cm}$ with a $0.25 \mathrm{~mm}$ coating (Kieselgel 60), were obtained from Merck. $p$-Propylbenzene sulfonic acid solid-phase extraction columns were prepared with $2 \mathrm{~g}$ of Bulk Isolute ${ }^{\mathrm{TM}} \mathrm{SCX}$ sorbent (International Sorbent Technologies).

Preparation of anhydrous butterfat. Prior to the interesterification reactions, the butter was treated according to the procedure of Kalo et al. (8) with slight modifications: water was separated from butter in a separatory funnel at $60^{\circ} \mathrm{C}$, and fat was filtered out (with normal filter paper) and dried in vacuum $(c a .800 \mathrm{mb})$ in a boiling water bath for $1 \mathrm{~h}$. Nitrogen (after drying by passage through an ampoule with silica gel) was bubbled into the melted dried butterfat for $c a .1 \mathrm{~h}$ (to help remove residual oxygen and water), and the (anhydrous) butterfat thus obtained was stored in sealed packages at $-30^{\circ} \mathrm{C}$ until experimental use.

Protein determinations. The amount of protein adsorbed on the hollow fibers of the reactor was obtained as the difference between the protein content of the supernatant solution 
before immobilization and after immobilization. The assays for protein followed the method described by Robyt and White (16), later modified by Balcão et al. (17).

Immobilization of lipase. Because of the hydrophobic character of the hollow fibers, the reactor was prewet by rinsing with a series of liquids prior to every immobilization of enzyme: absolute ethanol for $c a .15 \mathrm{~min}$ (to fill the pores in the fibers completely and assist in removal of air bubbles), ultrapure water for $c a .15 \mathrm{~min}$ (to strip ethanol away), and McIlvaine buffer (18) for $c a .10 \mathrm{~min}$ (to establish the convenient $\mathrm{pH})$. For each experiment, $250 \mathrm{~mL}$ of lipase solution [1.692 $\mathrm{g}$ of crude lipase powder per liter of Mcllvaine buffer (17)] was poured into a stirred beaker and recirculated for $c a .10 \mathrm{~h}$ through both the lumen and the shell sides of the fibers in the module at a flow rate of $c a .112 \mathrm{~mL} / \mathrm{h}$ with a high-precision metering pump. After each reaction experiment, and before the next experiment, the hollow-fiber module was rinsed with diethyl ether and ethanol (50\%, vol/vol) for $c a .20 \mathrm{~min}$ (to remove butterfat and adsorbed protein) and with ultrapure water for $c a .15 \mathrm{~min}$ (to strip diethyl ether/ethanol away from the membrane pores); from then on, the procedure was as described above.

Interesterification/hydrolysis reactions. All butterfat modification reactions were carried out at $40^{\circ} \mathrm{C}$ with the experimental setup depicted in Figure 1. This setup encompasses a hollow-fiber bioreactor unit, immersed in a water bath that was kept at $40 \pm 0.5^{\circ} \mathrm{C}$ and equipped with a mechanical agitator and a digital temperature controller. Upon completion of the lipase immobilization procedure, and immediately before startup of each experiment, the following sequence of procedures was followed: the reactor was placed upside down, and the dry butterfat feedstock was pumped through the reactor (to replace the aqueous buffer in the lumen and shell sides of the fibers completely); the reactor was reverted to its regular operating position (inlet streams at the bottom); and butterfat was then circulated for an extra 2 min (before starting the stopwatch). The whole system was kept under a transparent dome with the air temperature controlled at $40 \pm 3^{\circ} \mathrm{C}$ (to prevent solidification of the butterfat in the tubing). Recirculation of the melted butterfat through the reactor was accomplished by means of two high-precision metering pumps. Volumes of butterfat of $375 \mathrm{~mL}$ were recirculated for $c a .150 \mathrm{~h}$ through the lumen side and shell side of the hollow fibers at flow rates of $35 \mathrm{~mL} / \mathrm{h}$ and $31 \mathrm{~mL} / \mathrm{h}$, respectively (to achieve similar space times in both sides). Throughout each experiment, dried nitrogen was bubbled into the melted fat in the beaker (to assist in water and oxygen removal and thus prevent hydrolysis and oxidation). Aliquots were withdrawn at regular time intervals from the beaker with the recirculating fat and were assayed for free fatty acids, TAG, fatty acid residues, water, and thermal behavior.

Determinations of free fatty acids. Free fatty acids in butterfat were analyzed by high-performance liquid chromatography by the procedure of Garcia et al. (19) with modifications $(20,21)$.

Isolation and fractionation of TAG. TAG of the samples withdrawn from the reaction medium were isolated by thinlayer chromatography (TLC). The plates were developed with hexane/diethyl ether/formic acid (80:20:1.6, vol/vol/vol) according in general to the procedure described by Christie (22). After spraying with 2,7-dichlorofluorescein $(0.19 \%$ in ethanol), TAG were extracted from the silica gel matrix with chloroform/methanol $(98: 2, \mathrm{vol} / \mathrm{vol})$.

TAG of the original reaction mixture and of the reaction products were fractionated into saturated, monounsaturated, and polyunsaturated fractions by silver-ion chromatography with appropriate extraction columns $(2 \times 12 \mathrm{~cm})$ loaded with $p$-propylbenzene sulfonic acid, as described in detail by

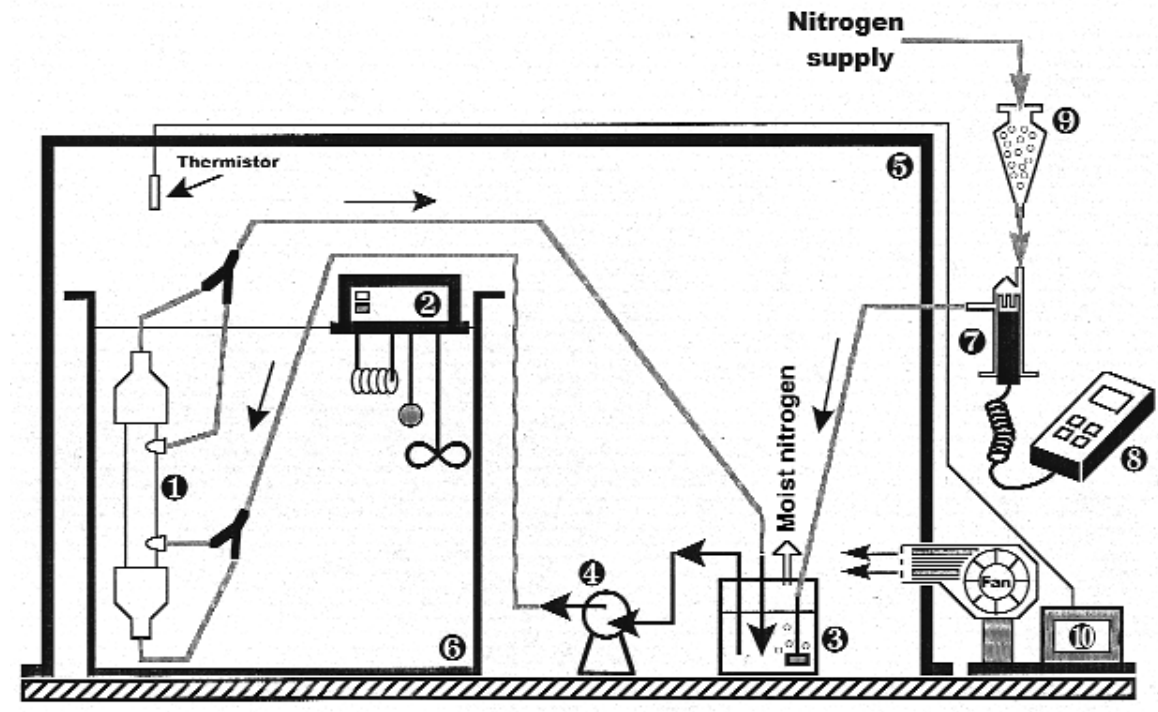

FIG. 1. Experimental setup for the lipase-catalyzed interesterification reactions in butterfat. (1, Hollow-fiber bioreactor, (2, temperature controller, 3, stirred beaker with melted butterfat, $\mathbf{4}$, high-precision gear pumps, $\mathbf{5}$, transparent dome, $\boldsymbol{\theta}$, water bath, $\boldsymbol{\theta}$, moisture probe, $\boldsymbol{8}$, thermohygrometer, $\mathbf{9}$, ampoule with silica gel, (10,blower/electronic control. 
Kemppinen and Kalo (23). The stepwise elution scheme was as follows: $35 \mathrm{~mL}$ of pentane/dichloromethane (25:75) to recover the saturated fraction, $45 \mathrm{~mL}$ of acetone/dichloromethane (1:99) to obtain the monounsaturated fraction, and $40 \mathrm{~mL}$ of plain acetone to obtain the polyunsaturated fraction.

Determinations of TAG. TAG were analyzed with the Carlo Erba gas chromatograph and a capillary polarizable phenyl $(65 \%)$ methylsilicone column according to the procedures by Kalo et al. (24) and Kalo and Kemppinen (25), with modifications. After the injector was cool for $100 \mathrm{~s}$ with gaseous carbon dioxide, injection of sample volumes of $0.2-0.5 \mu \mathrm{L}$ of a $2-4 \mathrm{mg}_{\mathrm{TAG}} / \mathrm{mL}_{\text {isooctane }}$ mixture was made under constant pressure $(97.5 \mathrm{kPa})$ of carrier gas (hydrogen). Immediately after injection, the system was changed to constant-flow mode (linear velocity of $62 \mathrm{~cm} / \mathrm{s}$ ). The temperature program was as follows: after $1 \mathrm{~min}$ at $170^{\circ} \mathrm{C}$, the column temperature was increased $10^{\circ} \mathrm{C} / \mathrm{min}$ linearly to $310^{\circ} \mathrm{C}$, maintained at that temperature for $1 \mathrm{~min}$, increased $0.5^{\circ} \mathrm{C} / \mathrm{min}$ linearly to $315^{\circ} \mathrm{C}$, maintained at that temperature for $1 \mathrm{~min}$, increased $8^{\circ} \mathrm{C} / \mathrm{min}$ linearly to $360^{\circ} \mathrm{C}$, and finally maintained at that temperature for $12 \mathrm{~min}$. The temperature of the detector was set at $360^{\circ} \mathrm{C}$. All samples were dissolved in an isooctane solution with tripelargonin $(83.6 \mathrm{ng} / \mu \mathrm{L})$ as internal standard. A linear calibration curve was made by triplicate analyses of five isooctane solutions of monoacid TAG of tributyrin (BBB), tristearin (SSS), and triolein (OOO), ranging from 125 to $2500 \mu \mathrm{g}_{\mathrm{TAG}} / 5 \mathrm{~mL}_{\text {mixture }}$, and tricaproin (CoCoCo), tricaprylin (CyCyCy), tricaprin (CiCiCi), trilaurin (LaLaLa), trimyristin (MMM), and tripalmitin (PPP) from 62.5 to $1250 \mu \mathrm{g}_{\mathrm{TAG}} / 5 \mathrm{~mL}_{\text {mixture }}$, and the same concentration of internal standard (tripelargonin) as described in detail elsewhere (26). The parameters of the calibration curves were determined by linear regression of the calibration data; correlation coefficients were always greater than 0.993 . The parameters for other TAG were calculated by interpolation relative to the number of carbon atoms by using a nonlinear regression fit of the slopes of the calibration lines (response factors) as function of the number of carbon atoms (the correlation coefficient of the nonlinear regression was 0.999 ) by means of the program TableCurve ${ }^{\mathrm{TM}} \mathrm{V}$. 1.0 (Jandel Scientific, San Rafael, CA). For identification of TAG, gas chromatograms of butterfat samples with added monoacid TAG standards (BBB, $\mathrm{C}_{12} ; \mathrm{CoCoCo}, \mathrm{C}_{18} ; \mathrm{CyCyCy}, \mathrm{C}_{24}$; $\mathrm{CiCiCi}, \mathrm{C}_{30}$; LaLaLa, $\mathrm{C}_{36}, \mathrm{MMM}, \mathrm{C}_{42} ; \mathrm{PPP}, \mathrm{C}_{48}$; and SSS, $\mathrm{C}_{54}$ ) were analyzed. For determination of (standard) retention indices, 23 equimolar mixtures of three standard monoacid TAG were interesterified with sodium methoxide (thus yielding 112 different TAG species), as described in detail by Kemppinen and Kalo (26), and the resulting products were analyzed by GC as described above. Retention indices were calculated by the cubic spline curve-fitting method with the software MICMAN ${ }^{\circledR}$ (HNU-Nordion, Helsinki, Finland). Major TAG in original and lipasemodified butterfat samples were identified by comparison of the retention indices to those of synthesized mixtures of TAG (26).
Determinations of fatty acid residues. After preliminary purification by TLC, the composition of fatty acid residues in TAG before and after enzymatic reaction were determined with the MicroMat gas chromatograph. The FAME were separated on a HP-Innowax silica capillary column with helium as carrier gas (inlet pressure 1.2 bar). The temperature of the FID was $250^{\circ} \mathrm{C}$, and the injector was maintained at $225^{\circ} \mathrm{C}$ and operated at a split mode of $1: 20$. The temperature program was: $3 \mathrm{~min}$ at $50^{\circ} \mathrm{C}$, linear increase of temperature at $10^{\circ} \mathrm{C} / \mathrm{min}$ to $195^{\circ} \mathrm{C}$, holding at $195^{\circ} \mathrm{C}$ for 1 min, linear increase of temperature at $1^{\circ} \mathrm{C} / \mathrm{min}$ to $220^{\circ} \mathrm{C}$, and holding at $220^{\circ} \mathrm{C}$ for $5 \mathrm{~min}$. The TAG (before reaction) were transesterified to methyl esters with sodium methoxide in methanol as follows: from the (TLC-purified) TAG in chloroform, sufficient volume $(100 \mu \mathrm{L})$ was withdrawn to contain ca. $5 \mathrm{mg}$ of TAG and poured into a screw-capped vial. Solvent was then evaporated under a gentle stream of nitrogen, and $300 \mu \mathrm{L}$ hexane was added, followed by addition of $3 \mu \mathrm{L}$ of sodium methoxide ( $2 \mathrm{~mol} / \mathrm{L}$ in methanol). After vigorous mixing for ca. $1 \mathrm{~min}$ in a vortex mixer, centrifugation at 800-1000 rpm was performed for $c a$. $10 \mathrm{~min}$, and $1 \mu \mathrm{L}$ of clear supernatant was immediately injected. For TAG obtained as reaction products, the methylation procedure was slightly different: $10 \mu \mathrm{L}$ of melted reaction product was accurately weighed into a screw-capped vial, and $1.0 \mathrm{~mL}$ of TAG27 solution $(41.8 \mathrm{mg} / 500 \mathrm{~mL}$ isooctane) was added. Solvent was then evaporated under a gentle stream of nitrogen (at $c a .40^{\circ} \mathrm{C}$ ), and $600 \mu \mathrm{L}$ hexane was added, followed by addition of $6 \mu \mathrm{L}$ of sodium methoxide $(2 \mathrm{~mol} / \mathrm{L}$ in methanol). When transesterifying acylglycerols of samples of reaction products, in addition to the catalytic amount of sodium methoxide, a sufficient amount of this compound was also added to neutralize the free fatty acids according to the procedure described by Badings and De Jong (27). After vigorous mixing for $c a$. $1 \mathrm{~min}$ in a vortex, centrifugation at 800-1000 rpm was performed for $c a$. $10 \mathrm{~min}$, after which $1 \mu \mathrm{L}$ of clear supernatant was immediately injected. Mass and molar response factors for FAME of interest were determined by analyzing a standard mixture (GLC74); seven injections of $1 \mu \mathrm{L}$ of a $1 \%$ solution (wt/vol) of GLC74 in hexane were accordingly made. For identification of branched-chain fatty acids, two standard mixtures were analyzed (89-1052 Qual Mix BR2 and 89-1054 Qual Mix BR4). For other FAME, molar response factors were calculated by interpolation based on the nonlinear fit of the (average) molar response factors for FAME from GLC74 as a function of the number of carbon atoms (correlation coefficient of nonlinear regression was 0.999 ) by using the program TableCurve ${ }^{\mathrm{TM}}$.

Determinations of water content. Moisture contents of the substrates (butterfat) were determined via coulometry. Melted butterfat was weighed in a warm syringe, injected promptly into the Karl Fischer reaction vessel, and titrated with in situgenerated iodine until the equivalence point.

Analysis of thermal behavior. Thermal analysis of regular and modified butterfat was accomplished by differential scan- 
ning calorimetry with high-pressure aluminum cells sealed under nitrogen. Regular and modified butterfat samples, weighing typically $10-30 \mathrm{mg}$, were frozen to $-40^{\circ} \mathrm{C}$ with liquid nitrogen and heated afterward to $80^{\circ} \mathrm{C}$ at $8^{\circ} \mathrm{C} / \mathrm{min}$; thermograms were analyzed for onset and end of melting, major peak maxima temperatures, and enthalpy of melting $\left(\mathrm{J} / \mathrm{g}_{\text {butter- }}\right.$ fat).

Determination of fatty acid residues at the sn-2 position. A fat sample was hydrolyzed with pancreatic lipase at $\mathrm{pH} 8.0$ as described elsewhere (28). The diethyl ether extract of the hydrolysate was applied as a band on a silica gel $\mathrm{G}$ plate (with a film thickness of $0.25 \mathrm{~mm}$ ), and the plate was eluted with hexane/diethyl ether/acetic acid (70:20:4). The monoacylglycerol band was scraped off the plate into a Pasteur pipette plugged with glass wool. The monoacylglycerols were eluted with $5 \mathrm{~mL}$ of $10 \%$ methanol in hexane (vol/vol) and, after evaporation of the solvent, they were transesterified with sodium methoxide in hexane to methyl esters, as described above.

\section{RESULTS}

The protein content of the crude M10 ${ }^{\mathrm{TM}}$ lipase powder was $9.74 \%$ (w/w) (bovine serum albumin equivalent). The amount of protein adsorbed onto the hollow fibers was $6.36 \pm$ $0.89 \mu \mathrm{g}_{\text {protein }} / \mathrm{cm}^{2}$ membrane and corresponded to an immobilization yield of $c a .54 \%$ of the protein in the supernatant solution. The water content of the butterfat feedstock ranged from $352 \mathrm{ppm}$ in the beginning to $299 \mathrm{ppm}$ after $150 \mathrm{~h}$ of reaction. The (dried) nitrogen bubbling in the reactant mixture had an average relative humidity of $c a .0 .5 \%$ throughout the entire reaction time frame.

The thermograms of original butterfat and butterfat after lipase-mediated interesterification are depicted in Figure 2. Although the melting curves for the selected reaction times are similar in shape to one another, a widening of the overall temperature range between the peaks of the low-melting and high-melting fractions could be noticed, with important differences in the peak temperature of the shorter-chain TAG (viz., the first peak has changed from $17.13^{\circ} \mathrm{C}$ and absorption

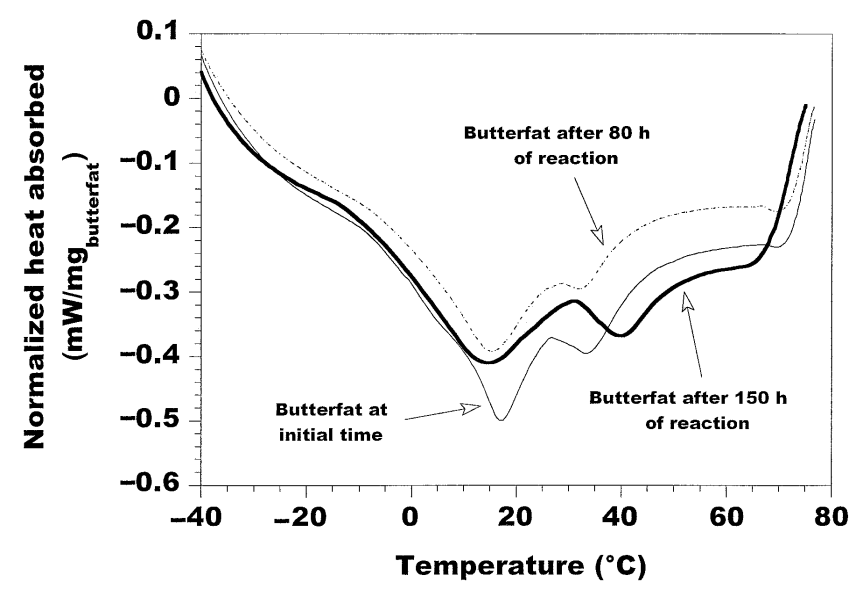

FIG. 2. Thermograms of original and lipase-modified butterfat.

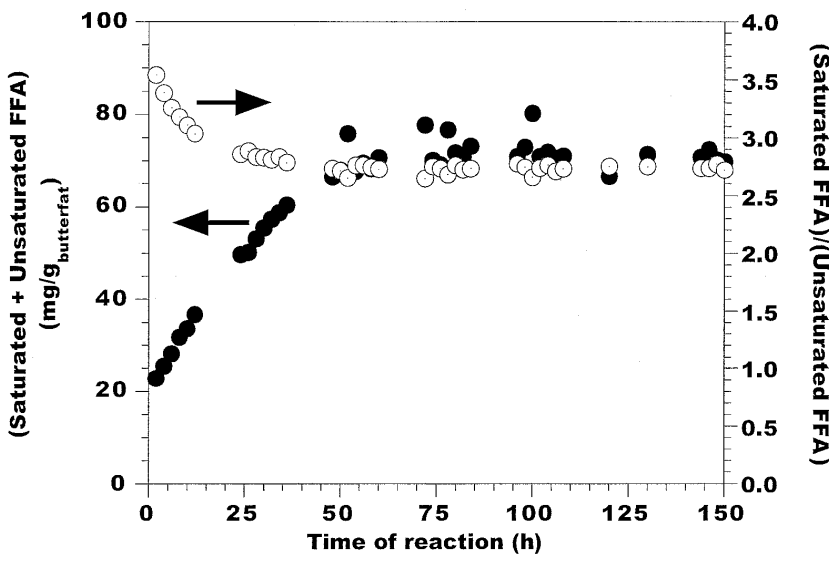

FIG. 3. Evolution of total concentrations of free fatty acids (FFA, $\mathbf{0}$ ) and of the ratio of concentrations of saturated to unsaturated FFA $(\bigcirc)$ throughout reaction time.

of $19.24 \mathrm{~J} / \mathrm{g}_{\text {butterfat }}$ in the initial butterfat feedstock to $14.63^{\circ} \mathrm{C}$ and absorption of $24.46 \mathrm{~J} / \mathrm{g}_{\text {butterfat }}$ in the butterfat interesterified for $150 \mathrm{~h}$ ), and in the peak temperature of the longerchain TAG (viz., the second peak has changed from $33.28^{\circ} \mathrm{C}$ and absorption of $3.92 \mathrm{~J} / \mathrm{g}_{\text {butterfat }}$ in the initial butterfat feedstock to $39.83^{\circ} \mathrm{C}$ and absorption of $4.91 \mathrm{~J} / \mathrm{g}_{\text {butterfat }}$ in the butterfat interesterified for $150 \mathrm{~h}$ ). The peak area of the low-melting glycerides increased by $27.1 \%$, whereas the peak area of the high-melting glycerides increased by $25.3 \%$.

The total concentrations of free fatty acids in the reaction medium and the ratio of concentrations of free saturated fatty acids to free unsaturated fatty acids are depicted in Figure 3. To some extent release of free fatty acids was promoted by residual buffer trapped inside the hollow fibers prior to formal startup of sampling. This observation, which suggests an initial degree of hydrolysis of $c a .2 .5 \%$ at startup of interesterification of plain butterfat, is based on the total mass of fatty acid residues esterified in the TAG of butterfat, $312 \mathrm{~g}$ in $375 \mathrm{~mL}$ of original butterfat (see Fig. 4), and on the total mass of free fatty acid residues at startup, $c a .7 .8 \mathrm{~g}$ in the butterfat. After

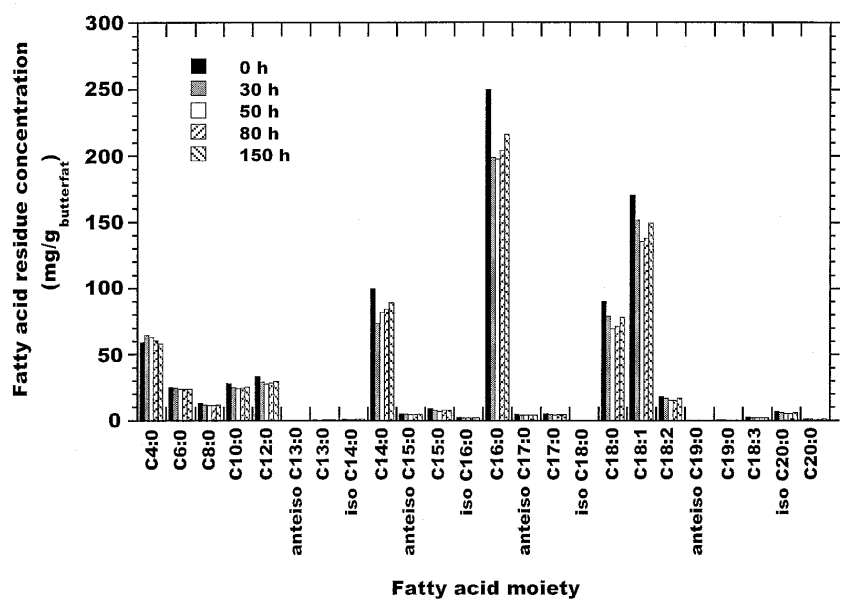

FIG. 4. Composition of (esterified) fatty acid moieties in the triacylglycerols of original and modified butterfat. 
startup of sampling, and during the entire reaction time frame, the increase in concentration of total free fatty acids was in agreement with the net reduction of $53 \mathrm{ppm}$ in the water content of the reaction medium. There is a slight degree of hydrolysis after time 0, as shown in Figure 3, which tends to be linear over the first $50 \mathrm{~h}$ of reaction and which corresponds to a net hydrolysis rate of $968.4 \mu \mathrm{g}_{\text {Total FFA }} /\left(\mathrm{h} \cdot \mathrm{g}_{\text {butterfat }}\right)$; however, after this time period, a net disappearance of free fatty acids from the reaction medium could be noticed, which can be attributed to incorporation into the TAG of butterfat and which corresponds to a net disappearance rate of $9.94 \mu \mathrm{g}_{\text {Total }}$ $\mathrm{FFA} /\left(\mathrm{h} \cdot \mathrm{g}_{\text {butterfat }}\right)$. A similar linear trend was also observed for the ratio of concentrations of saturated to unsaturated free fatty acid residues (S/U), viz., a preferential net release of free unsaturated fatty acids was observed during the first $12 \mathrm{~h}$ of reaction, but as time of reaction proceeded, the ratio S/U seemed to stabilize, probably as a result of stabilization of the concentrations of free fatty acids.

The profile of fatty acid residues in plain butterfat and in modified butterfat throughout the reaction time is depicted in Figure 4. In recalling the average overall composition of plain butterfat as depicted in this figure, the average molecular weight of fatty acids esterified in butterfat is estimated as $212.5 \mathrm{~g} / \mathrm{mol}$. Furthermore, by assuming that the glyceride pool of butterfat is composed solely of TAG molecules and taking the density of butterfat at $40^{\circ} \mathrm{C}$ to be $0.905 \mathrm{~g} / \mathrm{mL}$ (29), the theoretical amount of fatty acids that could ever be released from butterfat by hydrolysis would be 918.9 $\mathrm{mg}_{\mathrm{FA}} / \mathrm{g}_{\text {butterfat }}$; using this value, coupled with the total concentrations of individual free fatty acids actually released by hydrolysis in our experiments, one can finally conclude that net overall hydrolysis of butterfat after startup occurred to an extent of $c a .5 .3 \%$. If the extent of hydrolysis promoted by residual buffer ( $c a .2 .5 \%$ ) trapped inside the hollow fibers is then subtracted from the total extent of hydrolysis, a value of $c a .2 .8 \%$ is obtained for the hydrolysis reaction that accompanies interesterification, which is consistent with the aforementioned decrease of $53 \mathrm{ppm}$ in the water content of the reaction medium. Because this degree of hydrolysis is below $5 \%$, the proportion of monoacylglycerols is negligibly low $(30,31)$, and so the molar concentrations of free fatty acids and diacylglycerols are similar $(30,31)$.

TAG with the same number of acyl carbon atoms but different degrees of unsaturation could be eluted as independent peaks. If one considers the total TAG in each acyl carbon number class in whole fat (see Figure 5A, with original reactants and reaction products after purification by TLC), several increases have occurred over the entire reaction time frame, viz., in the proportion of TAG 26 (99.1\%), TAG 28 (24.8\%), TAG 30 (21.4\%), TAG 32 (5.1\%), TAG $34(4.1 \%)$, TAG $46(8.0 \%)$, TAG 48 (14.9\%), and TAG 50 (12.4\%). Conversely, decreases in the proportions of some TAG could also be observed, viz., for TAG 36 (1.0\%), TAG 38 (2.8\%), TAG $40(5.5 \%)$, TAG $42(14.8 \%)$, TAG 44 (0.8\%), TAG 52 $(15.2 \%)$, and TAG $54(12.2 \%)$.
The reconstructed TAG compositions of the original reactant supply and the reaction product after $150 \mathrm{~h}$ of reaction, obtained by GC analysis of saturated, monoene, and polyene fractions, showed several important changes during the whole reaction time frame. In the acyl carbon number range of 28-46, the saturated TAG with two or three lauric, myristic, or palmitic acid moieties decreased $0.1-45 \%$ (on average, $13.0 \%$ ), as apparent from inspection of Figure 6A. A close inspection of Figure 5B (saturated fraction) reveals that (total) saturated TAG with acyl carbon numbers 30 and 54 displayed the lowest and highest percentage of decrease, respectively. The interesterification reaction has not significantly, or not at all, taken place at the $s n-2$ position, as expected for an $s n-1,3$-specific lipase; this conclusion is supported by the fact that the last trace in each group of peaks with the same acyl carbon number in the range of 36-42 was identified as the $s n$-2-butyryl or -caproyl isomer or a trace of sn-1(3)-butyryl or -caproyl monoene TAG (chromatograms not shown). Spontaneous acyl migration, or intramolecular transfer of one acyl moiety to an adjacent, unoccupied hydroxyl group on the glycerol backbone, might have taken place; it has been reported to be a spontaneous process that is dramatically accelerated by acids, bases, heat, and ion-exhange resins or charged immobilizing supports, in general (32). In the present situation, however, it is not likely that acyl migration into the $s n-2$ position played a significant role because the surface characteristics of the (hydrophobic) polypropylene hollow fibers are of an electrically neutral nature (33). Furthermore, because the fatty acid composition at the $s n-2$ position is important with regard to the nutritional properties of butterfat, we decided to investigate whether changes occurred in that position. Pancreatic lipase-mediated deacylation of TAG of native butterfat and of products by the end of the reaction time frame, followed by determination of the fatty acid composition of the 2-monoglycerides produced, led to the results depicted in Figure 7. Of the total fatty acid composition (see Fig. 4), myristic and palmitic acids in the $s n-2$ position were reduced by $2.1 \%$ and $0.1 \%$, respectively, whereas oleic and linoleic acids in the $s n-2$ position increased by $3.5 \%$ and $5.1 \%$, respectively (see Fig. 7). However, the results displayed in Figure 7 show that, in general, the proportions of fatty acids at the $s n-2$ position in the native and in the modified butterfat are similar, as expected for an interesterification reaction catalyzed by a sn-1,3-specific lipase.

Regarding the monoene fraction, TAG with acyl carbon numbers in the ranges of 28-34 and 48-54 increased 19.4-144.4\% (on average, 65.2\%) and 3.5-11.6\% (on average, $6.6 \%$ ), respectively (see Fig. 5C). A decrease of $2.2-5.4 \%, 5.0 \%$, and $0.4 \%$ for monoene TAG with one myristic, one lauric, or one palmitic acid moiety, respectively, could also be observed (see Fig. 6B). A close inspection of Figure 5C (monoene fraction) reveals that (total) monoene TAG with acyl carbon numbers 30 and 38 displayed the highest and lowest percentages of increase, respectively, and that monoene TAG with acyl carbon numbers 36 and 46 displayed the 


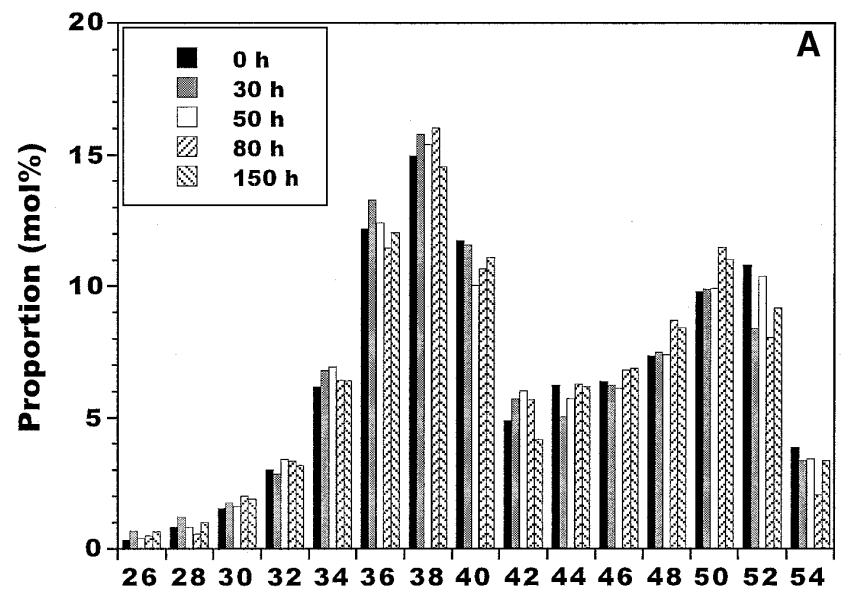

Number of acyl carbon atoms of triacylglycerol

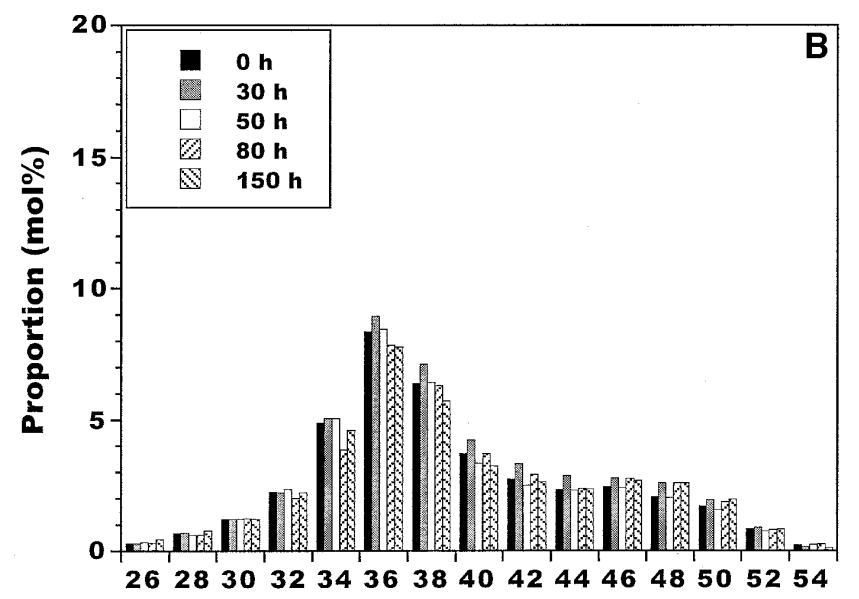

Number of acyl carbon atoms of triacylglycerol

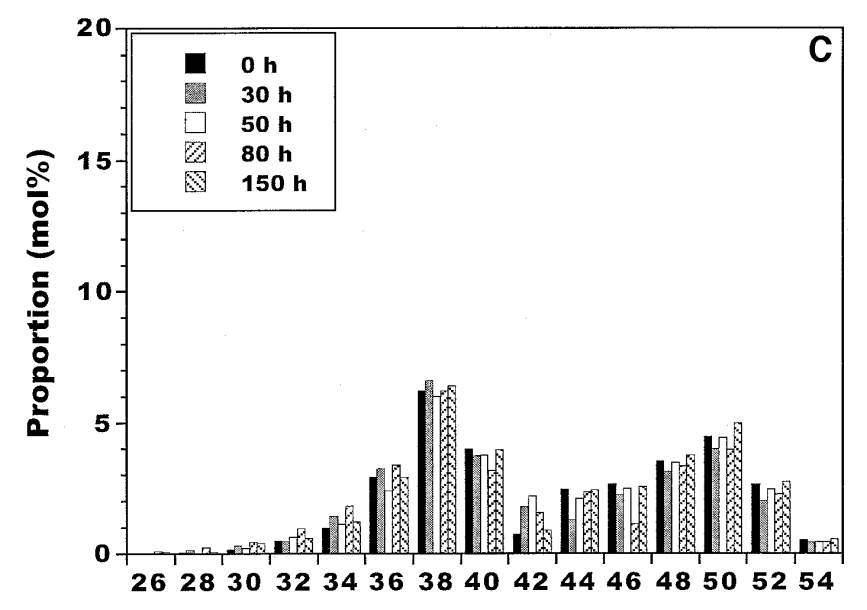

Number of acyl carbon atoms of triacylglycerol

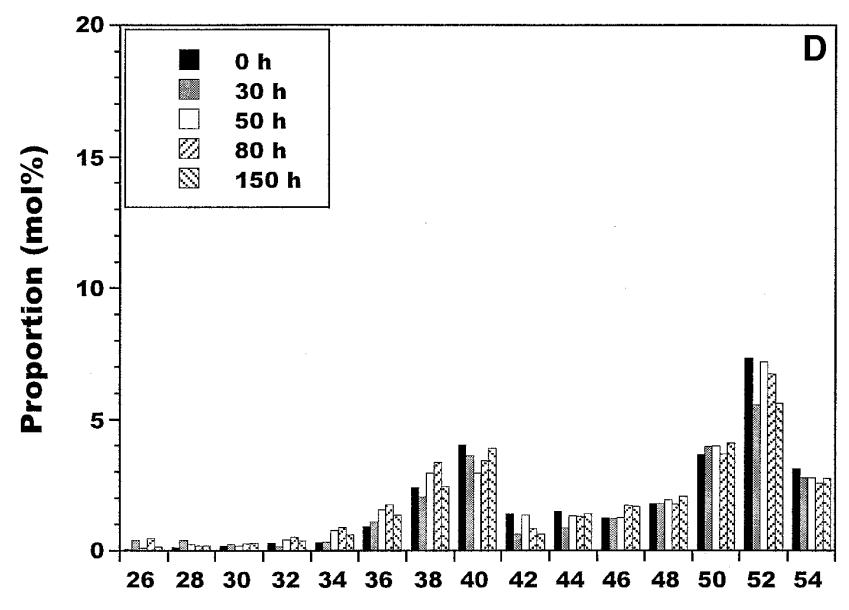

Number of acyl carbon atoms of triacylglycerol

FIG. 5. Triacylglycerol composition of original and lipase-modified butterfat samples after purification by thin-layer chromatography (A), and of saturated (B), monoene (C), and polyene (D) fractions.

lowest and highest percentages of decrease, respectively. Concerning the polyene fraction, TAG with acyl carbon numbers in the ranges 36-38 and 46-50 increased 1.7-49.7\% (on average, $25.7 \%$ ) and $12.2-32.0 \%$ (on average, $20.3 \%$ ), respectively, over $150 \mathrm{~h}$ of reaction (see Figs. 5D and 6C). A close inspection of Figure 5D (polyene fraction) reveals that total polyene TAG with acyl carbon numbers in the range of 36-48 displayed the highest percentages of increase.

As can be concluded from analysis of Figure 8, the total saturated TAG increase slightly during the first $30 \mathrm{~h}$ of reaction, but then they start disappearing continuously over the remaining reaction time frame (2.2\% net reduction). This observation is in agreement with the data displayed in Figure 3, which shows that the total content of free fatty acids in the reaction medium displays a threefold net increase within the whole reaction time frame. Regarding the monoene fraction, a 5.4\% net increase in the total monounsaturated TAG can be noticed over the same time frame, but the TAG that constitute the polyene fraction displayed a $2.9 \%$ net reduction. To assess whether the effects associated with the overall decrease in the saturated and polyene fractions and the overall increase in the monoene fraction are significant, linear regressions were performed to the data displayed in Figure 8. Computation of the $t$-ratio for each parameter (i.e., the ratio of the parameter estimate to the parameter confidence interval) led to the conclusion that the parameter estimate describing the linear rate of decrease of the saturated fraction and the linear rate of increase of the monoene fraction are acceptable (because the $t$-ratio is well above unity), whereas the null hypothesis that no increase exists is accepted for the parameter estimate describing the linear rate of increase of the polyene fraction.

As shown in Figure 9, (competitive) selective hydrolysis and interesterification of butterfat led to a preferential net release of myristic acid, when compared with the release of oleic acid, into the medium. As a matter of fact, a sharp (linear) increase in the ratio of concentrations of free myristic to free oleic acids could be observed during the first $24 \mathrm{~h}$ of reaction, and this trend continued as the experimental reaction proceeded, although after the first $24 \mathrm{~h}$ of reaction the increase was not as steep.

The TAG of interesterified butterfat had significantly less $(1.7-13.6 \%)$ saturated fatty acid residues; in particular, they 

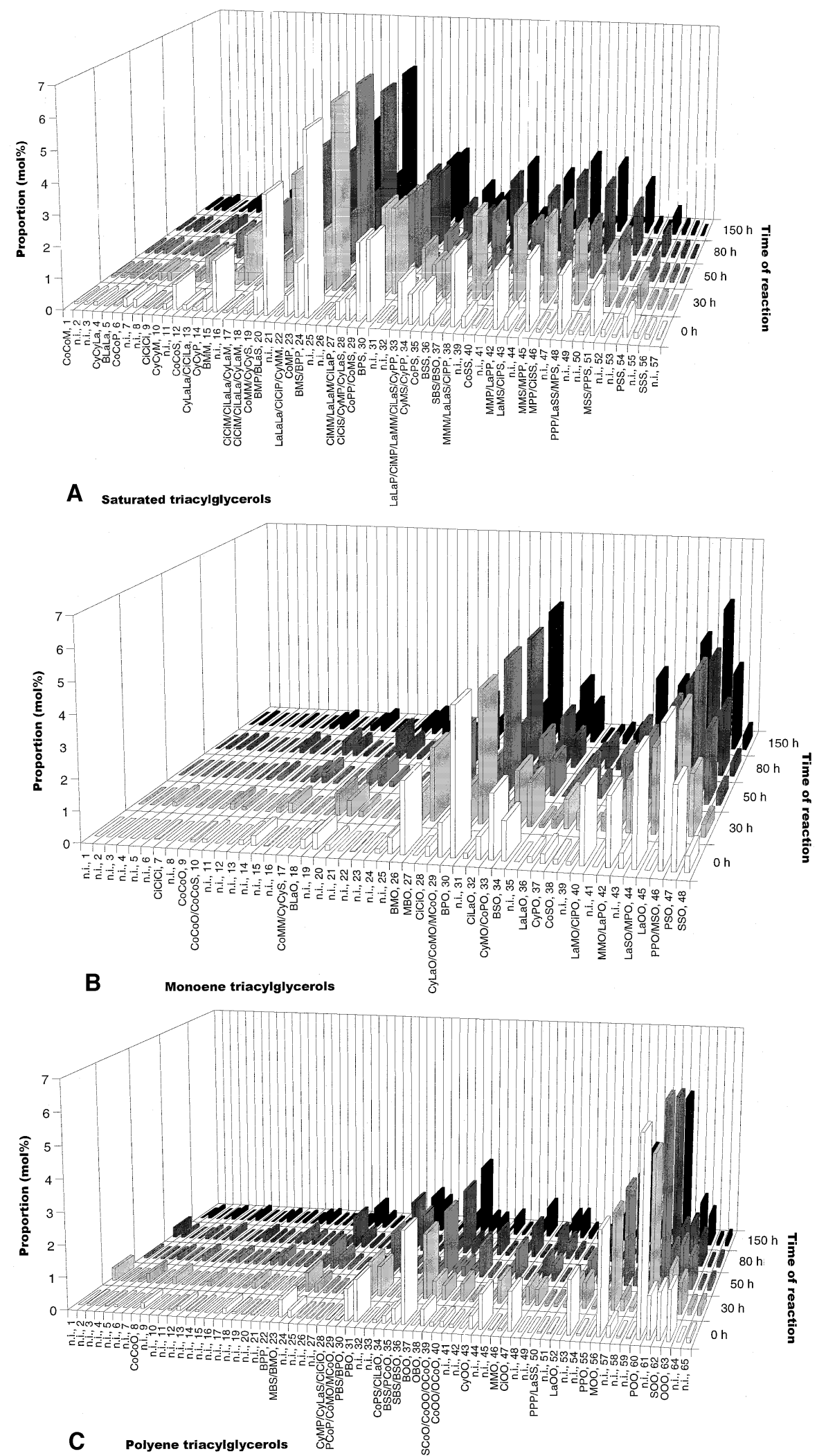

FIG. 6. Mole proportions of detected saturated triacylglycerols (TAG) (A, TAG 26: peaks 1-3; TAG 28: 4-8; TAG 30: 9-12; TAG 32: 13-16; TAG 34: 17-21; TAG 36: 22-26; TAG 38: 27-32; TAG 40: 33-37; TAG 42: 38-41; TAG 44: 42-44; TAG 46: 45-47; TAG 48: 48-50; TAG 50: 51-53; TAG 52: 54-55; TAG 54: 56-57), monoene triacylglycerols (B, TAG 26: peaks 1-2; TAG 28: 3-6; TAG 30: 7-11; TAG 32: 12-15; TAG 34: 16-23; TAG 36: 24-27; TAG 38: 28-31; TAG 40: 32-35; TAG 42: 36-39; TAG 44: 40-41; TAG 46: 42-43; TAG 48: 44-45; TAG 50: 46; TAG 52: 47; TAG 54: 48) and polyene triacylglycerols (C, TAG 26: peaks 1-2; TAG 28: 3-6; TAG 30: 7-9; TAG 32: 10-14; TAG 34: 15-20; TAG 36: 21-27; TAG 38: 28-33; TAG 40: 34-38; TAG 42: 39-41; TAG 44: 42-45; TAG 46: 46-49; TAG 48: 50-54; TAG 50: 55-59; TAG 52: 60-61; TAG 54: 62-65) in original and lipase-modified butterfat during the reaction. Abbreviations: B, butyric (4:0); Ci, capric (10:0); Co, caproic (6:0); Cy, caprylic (8:0); La, lauric (12:0); M, myristic (14:0); O, oleic (18:1); P, palmitic (16:0); and S, stearic (18:0) acids. n.i. = not identified. 


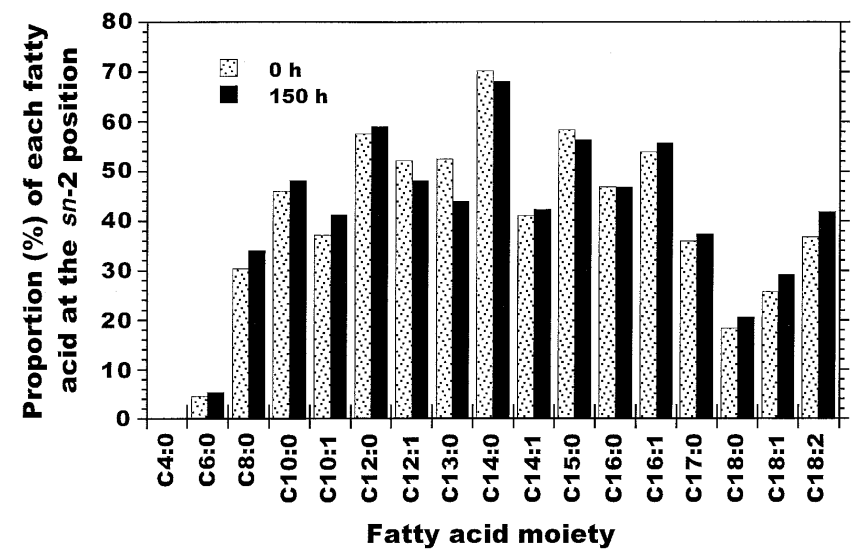

FIG. 7. Proportion (\%) of each fatty acid at the $s n-2$ position in the triacylglycerols of original and modified butterfat.

had $10.9 \%$ less lauric, $10.7 \%$ less myristic, and $13.6 \%$ less palmitic acid residues than those of the original butterfat, as depicted in Figure 4. This figure and Table 1 also show that esterified butyric and caproic acids decreased only 1.5 and $5.4 \%$, respectively, while the decrease of other major esterified fatty acids was $\mathrm{ca} .10 \%$ after the entire reaction time, thus confirming that the proposed goal of this research effort could be achieved without effecting major changes in the inventory of short-chain fatty acid residues, while concomitantly increasing the monoene proportion of TAG.

\section{DISCUSSION}

As apparent from inspection of Figure 3, a preferential net release of unsaturated (U), relative to saturated (S) fatty acid residues, existed especially during the first $50 \mathrm{~h}$ of reaction. However, as time of reaction proceeded, the ratio $\mathrm{S} / \mathrm{U}$ seemed to stabilize (probably because of the stabilization in the con-

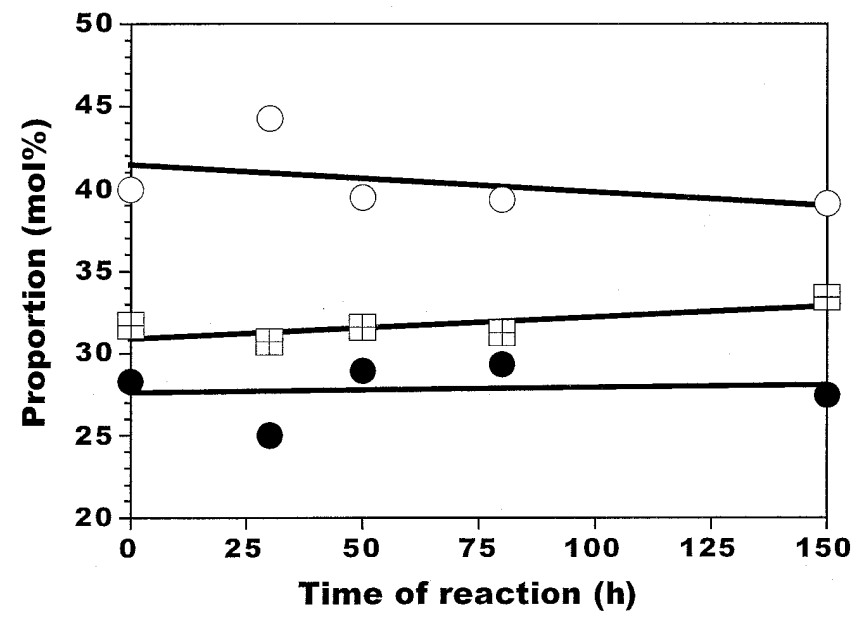

FIG. 8. Evolution of total (molar) proportions of triacylglycerols of the saturated $(\bigcirc)$, monoene $(\uplus)$, and polyene $(\bullet)$ fractions during reaction and associated linear rates of decrease of the saturated [(5.52 \pm 1.26$) \times$ $\left.10^{-3} \mathrm{~h}^{-1}\right]$ and polyene $\left[(5.85 \pm 8.30) \times 10^{-3} \mathrm{~h}^{-1}\right]$ fractions, and linear rate of increase of the monoene fraction $\left[(11.4 \pm 7.32) \times 10^{-3} \mathrm{~h}^{-1}\right]$.

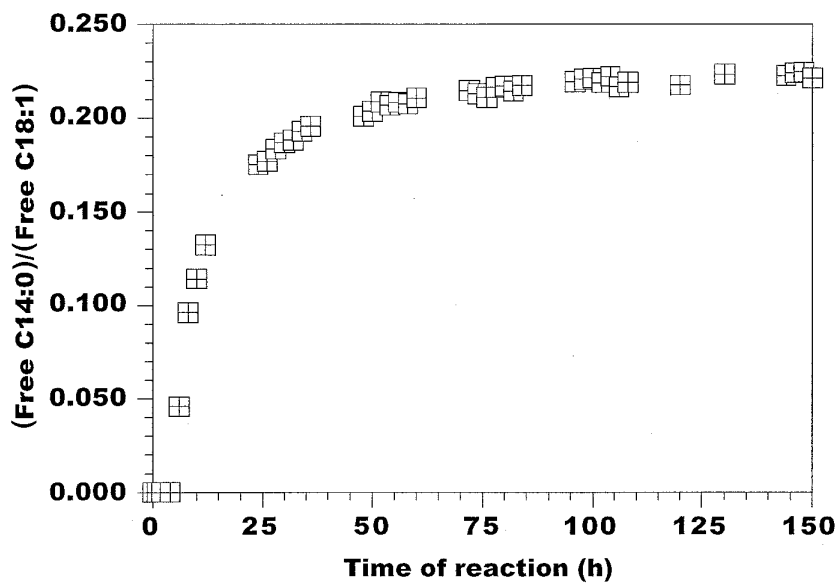

FIG. 9. Evolution of the ratio of concentrations of free myristic (14:0) to free oleic (18:1) acids throughout the reaction.

centrations of free fatty acids; see Fig. 3), thus indicating that hydrolysis and ester synthesis were balanced because of stabilization of the water content of the reaction medium. Inspection of Figure 4 also indicates preferential (net) release of lauric, myristic, and palmitic acid moieties, all of which have been claimed to be hypercholesterolemic $(4,34,35)$. These results are in agreement with the reported substrate specificity of the microbial lipase from M. javanicus (15). As can be seen in Figure 4, the amounts of short-chain fatty acids were not excessively affected, and because these compounds contribute to the fine buttery flavor, it is expected that this important characteristic will not be substantially affected in modified butterfat. Such fatty acids in free form can then be removed from the modified butterfat by solvent extraction,

TABLE 1

Net Changes in Esterified Fatty Acid Moieties

\begin{tabular}{lcc} 
Fatty acid & \multicolumn{2}{c}{ Percent variation (+: increase; - : decrease) } \\
\cline { 2 - 3 } moiety & Between 0 and $80 \mathrm{~h}$ & Between 80 and $150 \mathrm{~h}$ \\
C4:0 & +2.94 & -4.48 \\
C6:0 & -5.52 & +0.16 \\
C8:0 & -12.86 & +1.65 \\
C10:0 & -12.09 & +3.64 \\
C12:0 & -15.18 & +5.04 \\
C13:0 & -10.87 & +0.0334 \\
iso C14:0 & -7.46 & -0.30 \\
C14:0 & -15.51 & +5.69 \\
anteiso C15:0 & -12.48 & +3.23 \\
C15:0 & -14.25 & +2.44 \\
iso C16:0 & -14.28 & +3.66 \\
C16:0 & -18.39 & +5.80 \\
anteiso C17:0 & -16.92 & +5.50 \\
C17:0 & -18.70 & +4.96 \\
C18:0 & -20.97 & +9.69 \\
C18:1 & -19.11 & +8.44 \\
C18:2 & -18.60 & +11.54 \\
C19:0 & -47.89 & -4.77 \\
C18:3 & -17.42 & +4.71 \\
iso C20:0 & -19.80 & +8.33 \\
C20:0 & -27.44 & +17.30 \\
& &
\end{tabular}


using, e.g., a 1,2-butanediol/water (20:1 vol/vol) mixture (36), alkali refining, or short-path distillation.

Differential scanning calorimetry thermograms of plain and lipase-modified butterfat revealed transition states and allowed quantitation of the heat of fusion. The melting curves of original butterfat and butterfat interesterified for 80 and $150 \mathrm{~h}$ (see Fig. 2) are similar in shape to one another and resemble the melting curves obtained by other researchers (5). Because butterfat is a mixture of many different TAG (and some fatty acid moieties in free form), it exhibits a broad melting range (which increases from $16.2^{\circ} \mathrm{C}$ in plain butterfat to $25.2^{\circ} \mathrm{C}$ in the butterfat interesterified for $150 \mathrm{~h}$ ); our detailed observations (Fig. 2) are consistent with results obtained elsewhere $(5,9)$. The observed variation in melting profile with time may be accounted for by the considerable increase in the concentration of long-chain unsaturated fatty acids in free form (Figs. 3 and 4), which have a lower melting point than the saturated counterparts and will thus reduce the melting point of the lower-melting fraction, coupled with the concomitant decrease in the concentration of TAG that contain long-chain unsaturated fatty acid residues, which have a higher melting point and will thus increase the melting point of the higher-melting fraction. The thermogram of plain butterfat also shows that, for the low-melting TAG, the beginning and end of melting were 5.3 and $25.4^{\circ} \mathrm{C}$, respectively, while those for the high-melting TAG were 27.1 and $42.3^{\circ} \mathrm{C}$, respectively. The thermogram of lipase-modified butterfat obtained after $150 \mathrm{~h}$ of reaction shows that, for the low-melting TAG, the beginning and end of melting were -8.7 and $28.9^{\circ} \mathrm{C}$, respectively, while those for the high-melting TAG were 32.1 and $49.1^{\circ} \mathrm{C}$, respectively. A significant decrease in the endotherm of the low-melting fraction was also noticed after interesterification, as shown in Figure 2, which is consistent with results reported before (5). For both peaks of heat absorption (melting), net increases of 27.1 and $25.3 \%$ were found for the low-melting and high-melting fractions, respectively. It is known that every fat shows a direct relationship between the TAG composition and the physical properties exhibited; in particular, the types of fatty acid moieties esterified to the TAG backbone and their positions dictate the TAG's melting behavior. According to Rousseau et al. (5), TAG with a more asymmetrical distribution tend to display lower melting points. The hydrolysis that occurs during interesterification is a major factor for the changes observed in the low temperature range (37) because hydrolysis leads to formation of partial glycerides, mostly diacylglycerols.

The TAG composition of the reconstituted whole fat by the end of the reaction time frame is distinctly different from that obtained when plain butterfat is interesterified with a chemical catalyst (38) or when a nonspecific lipase, such as that from Pseudomonas fluorescens, is used in either the presence or the absence of solvents $(8,39)$. Interesterification of butterfat by chemical catalysts or nonspecific lipases leads to a distinct net increase in the proportions of TAG in the acyl carbon number range of 46-50. However, use of an sn-1,3-specific lipase, such as the one used in this research effort, leads to a preferential redistribution of fatty acids among the TAG molecules, so the total mole proportions of TAG molecules within the same acyl carbon number remains virtually unaltered when compared with the native butterfat.

The TAG in plain and lipase-interesterified butterfat displayed two major groups (see Fig. 5A), the first one composed of TAG with 26-40 carbon atoms, and the second one composed of TAG with 42-54 carbon atoms. As shown in Figure 5A, the predominant TAG in butterfat were TAG 36 (12.2 mol\%), TAG 38 (15.0 mol\%), TAG 40 (11.8 mol\%), TAG $50(9.8 \%)$ and TAG $52(10.8 \mathrm{~mol} \%)$. These major TAG undergo important net changes by $150 \mathrm{~h}$ of reaction, viz., decreases of $c a .1 .1,2.8,5.5$, and $15.2 \%$ for TAG 36, 38, 40, and 52, respectively, and an increase of $12.4 \%$ for TAG 50 .

Inspection of Figure 4 sheds light on some important changes that occur during interesterification. Although an increase in the concentration of butyric acid residues could be observed, especially in the first $30 \mathrm{~h}$ of reaction, such variation is offset after $150 \mathrm{~h}$, and similar trends were observed with other short-chain fatty acid moieties. The most noteworthy changes in the esterified fatty acids could be observed for myristic, palmitic, and stearic acids, with important net reductions of $10.7,13.6$, and $13.3 \%$, respectively, in the acylglycerols of butterfat that was modified for $150 \mathrm{~h}$. Oleic acid was also liberated, with a net reduction of $12.3 \%$. The hypercholesterolemic effect of such (essentially) saturated fats as butterfat in human diets is apparently associated mainly with lauric, myristic and palmitic fatty acid residues $(34,35)$, so the controlled release of such pernicious fatty acid moieties should add nutritional value to modified butterfat. Short-chain ( $\leq 6$ carbon atoms) and medium-chain ( $\leq 10$ carbon atoms) fatty acids, on the other hand, do not raise the cholesterol level (40). Of the long-chain fatty acid inventory, stearic acid has also been reported to be neutral in regard to the cholesterol level (35).

Recent studies of structured fats $(41,42)$ have shown that overall rates of absorption of palmitic and stearic acid residues were significantly greater, and excretion of the corresponding free fatty acids was significantly less, for fats that contained saturated long-chain fatty acids predominantly in the $s n-2$ position than for a control fat with a similar fatty acid composition but with the long-chain fatty acids predominantly at the $s n-1$ and $s n-3$ positions. Interesterification with a nonspecific lipase as catalyst (under microaqueous conditions) does not affect the proportions of esterified fatty acids but decreases the relative proportions of myristic and palmitic acids at the $s n-2$ position, thus improving the nutritional properties (8). In the present study, the hydrolysis that accompanied interesterification improved the nutritional properties of butterfat by decreasing the total proportions of esterified lauric, myristic, and palmitic acids, whereas interesterification itself did not significantly decrease the proportions of these fatty acid residues in the $s n-2$ position. However, the net (although small) decrease of $2.1 \%$ and $0.1 \%$ for myristic and palmitic acids, respectively, in the $s n-2$ position and the net increase of $3.5 \%$ for oleic acid in the $s n-2$ position (Fig. 7), 
possibly resulting from spontaneous acyl migration as discussed above, also suggest that the nutritional value of the modified butterfat by the end of the reaction time is in fact slightly superior to its native counterpart.

Further inspection of Figure 4 also suggests that hydrolysis and synthesis took place sequentially in the TAG of butterfat, as implied by the initial decrease and subsequent increase in the amounts of esterified residues. This conclusion is further backed up by inspection of Table 1, where the net changes in fatty acid residues are listed.

Separation of TAG in solid-phase columns loaded with silver ions is mainly due to formation of adducts between silver ions and double bonds of unsaturated TAG and, to a lesser extent, to the nonpolar interactions of the $p$-propylbenzene ring (23). Identification of the several TAG pooled in the three fractions of plain butterfat and of the reaction product with reaction time was based on comparison with the retention indices reported by Kemppinen and Kalo (26) for a wide spectrum of synthesized TAG. According to Christie (43), three major populations of TAG can be found in milkfat. One is composed of 48-54 carbon atoms and is rich in long-chain fatty acids and oleic acid. The second group is composed of $36-46$ carbon atoms and is of similar structure as the first group, except that the $s n-3$ position is often esterified with short-chain fatty acids. The third population is composed of 26-34 carbon atoms and is rich in medium- and short-chain fatty acids. These trends were prevalent in our original butterfat, as concluded from analysis of Figure 5A. As apparent from inspection of Figure 6A, important net reductions in the proportion of saturated TAG that contained myristic acid (M) have occurred over the entire reaction time, namely in the following species (which could be identified beyond doubt): СуСуМ (17.0\%), ВММ (0.1\%), ВMP (10.3\%), СoМP (6.4\%), BMS (8.9\%), CiMM/LaLaM (4.4\%), CyMP (23.3\%), CiMP/LaMM (4.6\%), MMM (2.9\%), MMP (0.5\%), CoMS (10.2\%), CyMS (16.9\%), and MPP (45\%). Despite the overall decrease of concentration of TAG that contained oleic acid (as concluded by inspection of Fig. 4), a net increase in the amounts of some TAG with oleic acid (O) has been found, especially for $\mathrm{CoCoO}(169.2 \%), \mathrm{BLaO}(34.4 \%), \mathrm{CiCiO}$ (12.7\%), CyPO (8.4\%), CoSO (118.1\%), PSO (3.5\%), SSO (3.8\%), $\mathrm{LaLaO}$ (11.9\%), and PPO (11.6\%) (see Figs. 5C, 6B, and $6 \mathrm{C}$ ). Figure 5B reveals that important net reductions of (saturated) TAG with 36-40 acyl carbons have occurred, and it also suggests that the same behavior is observed as for esterified fatty acid moieties, viz., hydrolysis followed by esterification. As pointed out before, the most significant variation in the saturated TAG family was noticed for MPP (net reduction of 45.0\%), CyMP (net reduction of 23.3\%), СуСуM (net reduction of $17.0 \%$ ), and CyMS (net reduction of 16.9\%). The fraction of TAG with (at least) one double bond (see Fig. 5D) exhibits two major groups, one centered at 40 and the other at 52 acyl carbon atoms; the TAG with 52 acyl carbons have undergone the greatest change, especially in terms of POO (with a net reduction of 18.5\%). However, other (poly)unsaturated TAG display completely opposite behavior over the whole reaction time, viz., net increases of $100 \%$ for BOO, $224.1 \%$ for $\mathrm{CoOO} / \mathrm{OCoO}$, and $100 \%$ for $\mathrm{LaOO}$.

The results obtained clearly show that alterations in the TAG structure of butterfat have been induced by the action of an immobilized (specific) lipase; they hence suggest that lipase-catalyzed interesterification (accompanied to some extent by net hydrolysis) of butterfat is a technically feasible alternative to sodium methoxide-catalyzed interesterification of butterfat for the purpose of producing butterfat with tentatively improved nutritional properties via depletion of the amounts of lauric, myristic, and palmitic acid-containing moieties, and increase in the proportion of (hypocholesterolemic) monoene TAG.

\section{ACKNOWLEDGMENTS}

Partial funding for this research effort was provided through grants by FLAD (Portugal; Project Lipase-catalyzed interesterification of butterfat with olive oil), Institut CANDIA (France; Project Modification de la matiére grasse par des lipases immobilisées sur un réacteur à membrane), Jenny \& Antti Wihuri Foundation (Finland), and by the Finnish Society of Dairy Science. Funding for author Victor M. Balcão was provided through Ph.D. fellowships by JNICT (Portugal; CIENCIA BD/2091/92-IF and PRAXIS XXI BD/5317/95). The authors are grateful to Freni K. Tavaria for the help during the startup of experiments and for free fatty acid analyses, and to MaijaLiisa Kuusela for technical assistance in TAG analyses.

\section{REFERENCES}

1. Larsson, K., Lipids-Molecular Organization, Physical Functions and Technical Applications, Oily Press, Dundee, 1994, pp. $1-41$.

2. Jensen, R.G., A.M. Ferris, and C.J. Lammi-Keefe, Symposium: Milkfat-Composition, Function, and Potential for Change, $J$. Dairy Sci. 74:3228-3243 (1991).

3. Deffense, E., Milkfat Fractionation Today-A Review, J. Am. Oil Chem. Soc. 70:1193-1201 (1993).

4. Kermasha, S., S. Kubow, M. Safari, and A. Reid, Determination of the Positional Distribution of Fatty Acids in Butterfat Triacylglycerols, Ibid. 70:169-173 (1993).

5. Rousseau, D., K. Forestière, A.R. Hill, and A.G. Marangoni, Restructuring Butterfat Through Blending and Chemical Interesterification. 1. Melting Behavior and Triacylglycerol Modifications, Ibid. 73:963-972 (1996).

6. Oba, T., and B. Witholt, Interesterification of Milkfat with Oleic Acid Catalyzed by Immobilized Rhizopus oryzae Lipase, J. Dairy Sci. 77:1790-1797 (1994).

7. Kimoto, H., Y. Endo, and K. Fujimoto, Influence of Interesterification on the Oxidative Stability of Marine Oil Triacylglycerols, J. Am. Oil Chem. Soc. 71:469-473 (1994).

8. Kalo, P., H. Huotari, and M. Antila, Pseudomonas fluorescens Lipase-Catalysed Interesterification of Butterfat in the Absence of a Solvent, Milchwiss. 45:281-285 (1990).

9. Kalo, P., P. Parviainen, K. Vaara, S. Ali-Yrrkö, and M. Antila, Changes in the Triglyceride Composition of Butter Fat Induced by Lipase and Sodium Methoxide Catalysed Inter-esterification Reactions, Ibid. 41:82-85 (1986).

10. Posorske, L.H., G.K. LeFebvre, C.A. Miller, T.T. Hansen, and B.L. Glenvig, Process Considerations of Continuous Fat Modification with an Immobilized Lipase, J. Am. Oil Chem. Soc. 65:922-926 (1988).

11. Macrae, A.R., Microbial Lipases as Catalysts for the Interesteri- 
fication of Oils and Fats, in Biotechnology for the Fats and Oils Industry, American Oil Chemists' Society, Champaign, 1984, pp. 189-198.

12. Macrae, A.R., Interesterification of Fats and Oils, in Proceedings of the International Symposium on Biocatalysts in Organic Syntheses, Noordwijkerhout, Holland, 1985, pp. 195-208.

13. Ohlson, P.R., Technological Development Ways in the Food Industries-Fat Industry, in Proceedings of the International Symposium on Technological Development Ways in Food Industries, Paris, December 1-2, 1983, pp. 103-120.

14. Safari, M., and S. Kermasha, Interesterification of Butterfat by Commercial Microbial Lipases in a Cosurfactant-Free Microemulsion System, J. Am. Oil Chem. Soc. 71:969-973 (1994).

15. De Greyt, W., and A. Huyghebaert, Lipase-Catalyzed Modification of Milkfat, Lipid Technol. (January):10-12 (1995).

16. Robyt, J.F., and B.J. White, Biochemical Techniques-Theory and Practice, Waveland (1990).

17. Balcão, V.M., M.C. Vieira, and F.X. Malcata, Adsorption of Protein from Several Commercial Lipase Preparations onto a Hollow-Fiber Membrane Module, Biotech. Prog. 12:164-172 (1996).

18. Dawson, R.M.C., W.H. Elliott, D.C. Elliott, and K.M. Jones, Data for Biochemical Research, Oxford Science Publications, Oxford, United Kingdom, 1969, p. 427.

19. Garcia, H.S., H.R. Reyes, F.X. Malcata, C.G. Hill, and C.H. Amundson, Determination of the Major Free Fatty Acids in Milkfat Using a Three-Component Mobile Phase for HPLC Analysis, Milchwiss. 45:757-759 (1990).

20. Balcão, V.M., and F. X. Malcata, Lipase-Catalyzed Modification of Butterfat via Acidolysis with Oleic Acid, J. Molecular Catalysis B: Enzymatic 3:161-169 (1997).

21. Balcão, V.M., A. Kemppinen, F.X. Malcata, and P. Kalo, Lipase-Catalyzed Acidolysis of Butterfat with Oleic Acid: Characterization of Process and Product, Enzyme Microb. Technol. 23 , in press.

22. Christie, W.W., Gas Chromatography and Lipids: A Practical Guide, The Oily Press, Ayr, 1989, pp. 37-39.

23. Kemppinen, A., and P. Kalo, Fractionation of the Triacylglycerols of Lipase-Modified Butteroil, J. Am. Oil Chem. Soc. 70:1203-1207 (1993).

24. Kalo, P., A. Kemppinen, and I. Kilpeläinen, Determination of Positional Distribution of Butyryl Groups in Milkfat Triacylglycerols, Triacylglycerol Mixtures, and Isolated Positional Isomers of Triacylglycerols by Gas Chromatography and Nuclear Magnetic Resonance Spectroscopy, Lipids 31:331-336 (1996).

25. Kalo, P., and A. Kemppinen, Mass Spectrometric Identification of Triacylglycerols of Enzymatically Modified Butterfat Separated on a Polarizable Phenylmethylsilicone Column, J. Am. Oil Chem. Soc. 70:1209-1217 (1993).

26. Kemppinen, A., and P.J. Kalo, Analysis of $s n-1(3)$ - and $s n-2-$ Short-Chain Acyl Isomers of Triacylglycerols in Butteroil by Gas-Liquid Chromatography, Ibid. 75:91-100 (1998).

27. Badings, H.T., and C. De Jong, Glass Capillary Gas Chromatography of Fatty Acid Methyl Esters. A Study of Conditions for the Quantitative Analysis of Short- and Long-Chain Fatty Acids in Lipids, J. Chromatogr. 279:493-506 (1983).
28. Hendrikse, P.W., and J.L. Harwood, Analytical Methods, in The Lipid Handbook, edited by F. D. Gunstone, J.L. Harwood, and F.B. Padley, Chapman and Hall, London, 1986, pp. 267-268.

29. Kurtz, F.E. The Lipids of Milk: Composition and Properties, in Fundamentals of Dairy Chemistry, edited by B.H. Webb and A.H. Johnson, AVI Publishing Company, Westport, 1965, p. 161.

30. Kalo, P., H. Huotari, and M. Antila, Pseudomonas fluorescens Lipase-Catalyzed Interesterification of Butterfat, Fat Sci. Technol. 91:276-280 (1989).

31. Kalo, P., P. Elo, and M. Antila, Determination of Mono- and Diacylglycerols, Free Fatty Acids and Cholesterol in Interesterified Butter Fat by Direct Gas Chromatography on a Capillary Column Coated with Immobilized Phenylmethylsilicone, Milchwiss. 43:416-422 (1988).

32. Bloomer, S., Lipase-Catalyzed Lipid Modifications in Nonaqueous Media, Ph.D. Thesis, Lund University, Lund, Sweden (1992).

33. Fureby, A.M., P. Adlercreutz, and B. Mattiasson, Acyl Migration and Its Implications in Lipid Modifications, Ann. NY Acad. Sci. 799:231-237 (1996).

34. Ney, D.M. Potential for Enhancing the Nutritional Properties of Milkfat, J. Dairy Sci. 74:4002-4012 (1991).

35. Vessby, B., Effects of Long-Chain Fatty Acids on Health in Man-Impacts of New Findings on Nutritional Recommendations, INFORM 5:182-185 (1994).

36. Keurentjes, J., Physical Chemistry and Engineering of Membranes for Fat/Fatty Acid Separations, Ph.D. Thesis, University of Wageningen, Holland, 1991, p. 7.

37. Kemppinen, A., P. Kalo, and M. Antila, Effects of Lipase-Catalyzed Interesterifications on Solid Fat Content of Butterfat, Meijeritieteellinen Aikakauskirja 46:48-55 (1988).

38. Hettinga, D., Butter, Edible Oil and Fat Products: Products and Application Technology, Vol. 3, in Bailey's Industrial Oil and Fat Products, edited by Y.H. Hui, Wiley, New York, 1996, pp. 40-60.

39. Kalo, P., H. Huotari, and M. Antila, Chemical Composition of Butterfat Interesterified with Pseudomonas fluorescens Lipase at Various Temperatures, Meijeritieteellinen Aikakauskirja 47:29-38 (1989).

40. Glaeser, H., and M. Keane, Cholesterol-Reduced Dairy Products-Healthy or Harmful? Dairy Ind. Int. 57:39 (1992).

41. Lien, E.L., The Role of Fatty Acid Composition and Positional Distribution in Fat Absorption in Infants, J. Pediatrics 125: 62-68 (1994).

42. de Fouw, N.J., G.A.A. Kivits, P.T. Quinlan, and W.G.L. van Nielen, Absorption of Isomeric, Palmitic Acid-Containing Triacylglycerols Resembling Human Milk Fat in the Adult Rat, Lipids 29:765-770 (1994).

43. Christie, N.W., The Composition and Structure of Milk Lipids, in Developments in Dairy Chemistry-2, edited by P.F. Fox, Elsevier Applied Science, London, 1983, p. 1. 